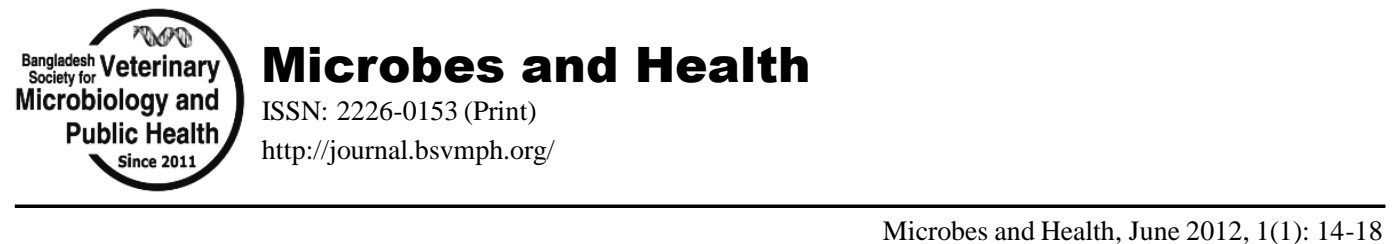

Microbes and Health, June 2012, 1(1): 14-18

\title{
Investigation on the Efficacy of a Killed Salmonella pullorum Vaccine
}

\author{
Mst. Shamima Akter, Sukumar Saha*, Md. Ariful Islam and Md. Golzar Hossain \\ Department of Microbiology and Hygiene, Faculty of Veterinary Science, Bangladesh Agricultural University, \\ Mymensingh-2202, Bangladesh.
}

${ }^{*}$ Corresponding author's e-mail: sukumar94@yahoo.com

[Received: 25 April 2012, Revised: 05 May 2012, Accepted: 30 June 2012]

\begin{abstract}
A B S T RA C T
This study was carried out to determine the efficacy of a formalin-killed alum-precipitated Salmonella pullorum vaccine prepared by the Livestock and Poultry Vaccine Research and Production Centre (LPVRPC), BAU, Mymensingh, Bangladesh. Immunization with this vaccine induced serum antibody titers that peaked in 2-week following both primary and booster vaccination $(P<0.05)$, and started to decline following 4 -week of both vaccinations. Both primary and booster vaccination induced detectable antibody responses that were able to react with whole cells $S$. pullorum as determined by passive haemagglutination test (PHA). Both vaccinated chicken and mice showed maximal resistance following challenge with a virulent isolate of $S$. pullorum $(P<0.01)$. In differential leukocyte counts in mice, a significant increase of lymphocytes was observed after primary immunization $(P<0.01)$. Sera from vaccinated chickens conferred superior protection over naive chickens from lethal challenge with $S$. pullorum $(P<0.01)$. Finally, this result indicates that $S$. pullorum vaccine is effective for controlling pullorum disease and antibody is crucial for protection.
\end{abstract}

Keywords: Vaccine, Immunization, Antibody, PHA Test

(C) 2012 Microbes and Health. All rights reserved

\section{Introduction}

Salmonella infections (Salmonellosis) are major problems for poultry industry in Bangladesh and have public health importance (Islam et al., 2007; Haider et al., 2008). The disease produced by Salmonella pullorum is called pullorum disease (also called bacillary white diarrhea), acute and chronic septicemic in nature; which is most significant because the causal agents of the disease are transmitted vertically from parents to offspring and mostly affect the growing stage (2-3 weeks of age) birds with great affinity to domestic fowl and turkey. But S. pullorum also isolated from other birds and mammals have little commercial significance in terms of disease production. The importance of salmonellosis in poultry sector has received great attention throughout the world. Among the infectious diseases, the prevalence of salmonellosis was recorded in breeding flock (Saleque et al., 2003). It is potentially responsible for various pathogenic processes in man and animals including poultry (Freeman, 1985).

The genus Salmonella, a member of the bacterial family Enterobacteriaceae (OIE, 2008), is a Gram-negative, non

Supplemental materials are available at- http://journal.bsvmph.org/

To cite this article: Akter MS, S Saha, MA Islam and MG Hossain, 2012. Investigation on the efficacy of a killed Salmonella pullorum vaccine, Microbes Health, 1(1): 14-18. spore-forming, non-flagellated and non-capsulated short rod, 1.0-2.5 $\mu \mathrm{m}$ in width, capable of producing septicemic disease in both domestic and wild birds (Buxton and Fraser, 1977). S. pullorum possesses the 1,9 , and $12 \mathrm{O}$ antigens.

The disease occurs worldwide, although effective control programs have reduced its incidence to low levels in many countries (Shivaprasad, 1997). As S. pullorum is a vertically transmitted disease, it has a great importance in context of Bangladesh and has been reported by several investigators (Hossain et al., 2006; Islam et al., 2006). The major emphasis for preventing infections is to avoid the introduction of pathogens into the farms by increased biosecurity (Gifford et al., 1987) along with vaccination (Barman et al., 2005). Vaccine available is both live (usually based on the Houghton 9R strain) and bacterins (killed/inactivated vaccine). If the parent birds are vaccinated against Salmonella spp, the chicks are protected by maternal antibodies in the hatchery ((Barman et al., 2005).

The Livestock and Poultry Vaccine Research and Production Center (LPVRPC) incorporated with its parent organization, the Department of Microbiology and Hygiene, Bangladesh Agricultural University (BAU) Mymensingh are producing a formalin-killed alum-precipitated S. pullorum (SP) vaccine. The vaccine is being tested for its purity, safety, potency and efficacy in the laboratory and field. Bashak (2011) and Das (2011) rep- 
orted that SP vaccine effectively induced antibody production and protected the vaccinated chicken against challenge infection, but the mechanism of protection still remains unknown. Therefore, present study was designed to assess the immunogenicity, protective activity and mechanism of protection of SP vaccine produced by LPVRPC, BAU, Mymensingh, Bangladesh.

\section{Materials and Methods}

\section{Study area and duration}

The present research was conducted at the Department of Microbiology and Hygiene, BAU, Mymensingh during the period of July 2011 to November 2011.

\section{Experimental mice and chicken}

A total of seventy (70) 10-week-old mice (Balb/c) were used in this study, collected from the Experimental Animal Shed of the Department of Microbiology and Hygiene, BAU, Mymensingh. Twenty 8-week-old layer birds (Shaver Brown strain) were selected. The birds were obtained with the courtesy of Phenix Hatchery Ltd., Gazipur. Another twenty 12-week-old High Sex Brown chicken were taken for passive protection testing which were not vaccinated with SP vaccine. The mice and birds were provided with nutrient diet, pure water, and other managemental requirements with proper bio-security.

Purity and safety test of Salmonella pullorum vaccine The SP vaccines were collected from LPVRPC, BAU. Five blood agar (BA) plates were inoculated with SP vaccines and incubated at $37^{\circ} \mathrm{C}$ for $24-48$ hours in the incubator for the growth of aerobic and anaerobic organism. Thus the collected SP vaccine which did not exhibit the growth of aerobic and anaerobic organism was used for vaccination. The safety test was carried out following the method of Dorsey (1963) and Matsumoto and Helfer (1977). Ten mice were inoculated subcutaneously (s/c) with $0.5 \mathrm{ml}$ of each vaccine and the vaccine considered safe if the inoculated mice remained alive and healthy during the observation period for 10 days.

\section{$\mathbf{L D}_{\mathbf{5 0}}$ dose determination in mice}

$S$. pullorum were cultured in nutrient broth overnight at $37^{\circ} \mathrm{C}$ in a shaker incubator and after 12 hours growth, centrifuged at $1500 \mathrm{rpm}$ for 5 minutes. Then the supernatant was decanted off and PBS was added and bacterial mass was re-suspended in PBS by shaking. This process was repeated three times. The pellet was then dissolved with sufficient amount of PBS and OD value was measured at $550 \mathrm{~nm}$ and the OD value was adjusted to 2.8 . A 250, 100, 50 and $25 \mu 1$ bacterial suspension or PBS were injected intra-peritonially in mice $(\mathrm{n}=10)$ of five different groups, respectively. Death pattern was monitored for subsequent 10 days. A 10 -fold dilution of the original suspension were made and spread on NA media for counting of CFU (S. pullorum: $\left.8.9 \times 10^{13} \mathrm{CFU} / \mathrm{ml}\right)$. A $25 \mu 1$ dose contained the $\mathrm{LD}_{50}$.

\section{Experimental immunization of chicken and mice}

Experimental chickens were divided into two groups; group A and group B. The chickens in group A $(n=10)$ were vaccinated with the SP vaccine following manufactu- rer's instructions, $0.5 \mathrm{ml}\left(0.625 \times 10^{10} \mathrm{CFU}\right)$ each, s/c, at 8 week of age for primary vaccination. These birds were revaccinated with a booster dose of the vaccine through $\mathrm{s} / \mathrm{c}$ route after 4-week (at 12-week of age) of primary vaccination. group $B$ chickens $(n=10)$ were kept as nonvaccinated controls. The experimental mice were divided into two groups; group A and group B. Group-A mice $(\mathrm{n}=10)$ were injected $\mathrm{i} / \mathrm{m}$ with the $\mathrm{SP}$ vaccine solution (100 $\mu \mathrm{l} /$ mouse) containing $1.25 \times 10^{10} \mathrm{CFU} / \mathrm{ml}$. A booster vaccination was given 4-week after the primary vaccination with the same dose. Mice in group B $(n=10)$ were considered as non-vaccinated control.

\section{Collection and preservation of sera}

The sera were collected from vaccinated chickens at 8 (before primary vaccination), 10 (after primary vaccination), 12 (after primary and before booster vaccination), 14 (after booster vaccination) and 16 (after challenge) weeks of age and from mice at 10 (before primary vaccination), 12 (after primary and before booster vaccination) 14 (after booster vaccination) weeks of age. Sera were collected from both non-vaccinated control chickens and mice at the same date. The collection and preservation of sera were accomplished according to the method described by Heddleston and Reisinger (1960).

\section{Passive haemagglutination (PHA) test}

The serological analysis was conducted by Passive Hemagglutination Assay (PHA) to determine the titer of antibody of the sera collected from both vaccinated and non vaccinated chickens and mice following the method described by Tripathy et al. (1970). Briefly, an amount of $50 \mu 1$ of PBS was first poured in each well up to $8^{\text {th }}$ well of horizontal row of microtiter plate. $50 \mu 1$ of test serum was added in the $1^{\text {st }}$ well. Two fold dilutions of serum ranging from 1:2 to $1: 256$ were made by transferring $50 \mu 1$ of the mixture from the $1^{\text {st }}$ well to $2^{\text {nd }}$ well and thus continuing successively up to the $8^{\text {th }}$ well from where an excess amount of $50 \mu$ of the mixture was poured off. A volume of $50 \mu 10.5 \%$ somatic antigen sensitized $\mathrm{hRBC}$ was taken in each of the eight wells. $9^{\text {th }}$ and $10^{\text {th }}$ well of horizontal row of microtiter plate was used for control. $50 \mu 1$ PBS and equal volume of control serum was added in the $9^{\text {th }}$ well and $50 \mu 1$ PBS and equal volume of sensitized RBC was added in the $10^{\text {th }}$ well. The content of the wells of the test system and control were mixed by gentle agitation of the microtiter plate and kept at room temperature for 4-5 hours. Agglutination resulting from mixing of test serum and somatic antigen sensitized $\mathrm{hRBC}$ in the test system was observed very carefully. Deposition of diffuse thin layer of clumping of hRBC on the bottom of the well considered as positive and the result were recorded. The PHA titer was the highest dilution of test sera where complete haemagglutination occur due to the reaction of specific antibody and antigen sensitized tanned hRBC.

The results of haemagglutination (HA) were recorded by the deposition of diffuse thin layer of clumping of RBC on the bottom of the wells, which indicated HA positive, and a compact buttoning with clear zone indicated HA negative. The reciprocal of the highest dilution of sensitized tanned hRBC was considered as titer of the serum. 


\section{Preparation of challenge dose}

Stock $S$. pullorum was cultured in $5 \mathrm{ml}$ nutrient broth at $37^{\circ} \mathrm{C}$ for overnight. Then an aliquot of the culture was inoculated into $50 \mathrm{ml}$ of fresh medium and further incubated at $37^{\circ} \mathrm{C}$ for another 12 hours in a shaker incubator. Then cultures were centrifuged and washed twice with PBS and adjusted to an OD of 2.80 at $550 \mathrm{~nm}$ wave length.

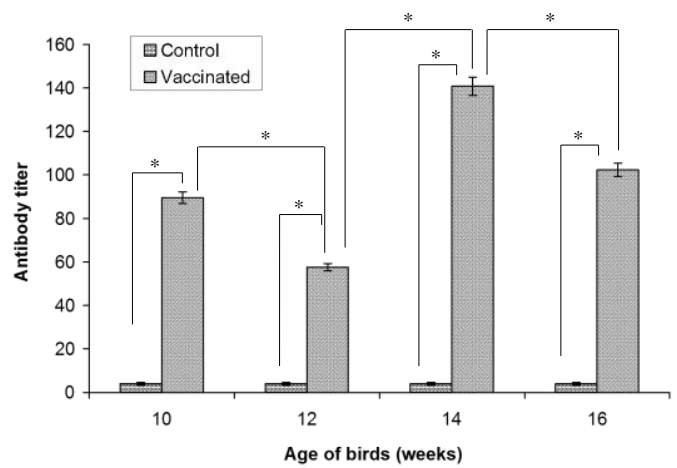

Fig. 1: Serum antibody titers against $S$. pullorum vaccination. Chickens were immunized at 8 -week of age and boosted at 12-week of age through $\mathrm{s} / \mathrm{c}$ route at the dose rate of $0.5 \mathrm{ml} / \mathrm{bird}\left(1.25 \times 10^{10} / \mathrm{ml} \mathrm{CFU}\right)$ Blood was drawn at 8-, 10-, 12-, 14-, and 16-week of age. Serum antibody titers against SP antigen were determined by PHA test. The graph shows the mean \pm SE values ( $\mathrm{n}=5$ chicken/group) ${ }^{*} P<0.05$ by student's $\mathrm{t}$-test.

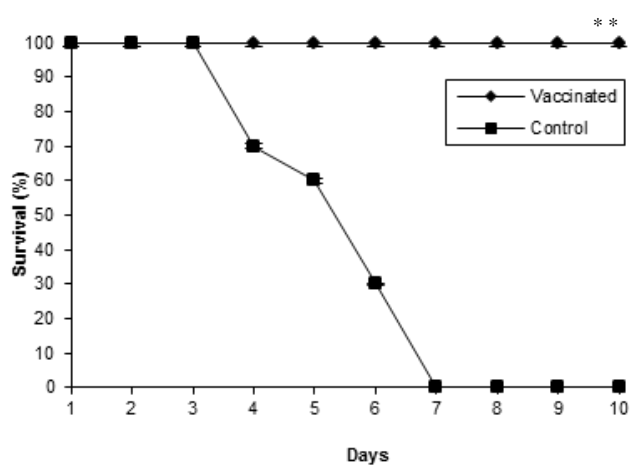

Fig. 2: Survival rate of chicken challenged intramuscularly with virulent isolate of $S$. pullorum. Chickens were immunized twice with SP vaccine at 8-week and boosted at 12-week of age of birds through $\mathrm{i} / \mathrm{m}$ route at the dose rate of $0.5 \mathrm{ml} / \mathrm{bird}\left(1.25 \times 10^{10} / \mathrm{ml} \mathrm{CFU}\right)$ Control chickens were injected twice with $0.5 \mathrm{ml}$ PBS/bird. Survival rate of chicken was monitored following $\mathrm{i} / \mathrm{m}$ challenge with $10 \mathrm{LD}_{50}$ dose $(0.25 \mathrm{ml})$ of mice. The survival rate was monitored for subsequent 10 days. (n=10 chicken per group). ${ }^{* *} P<0.01$ by Mantel-Cox Log rank test.

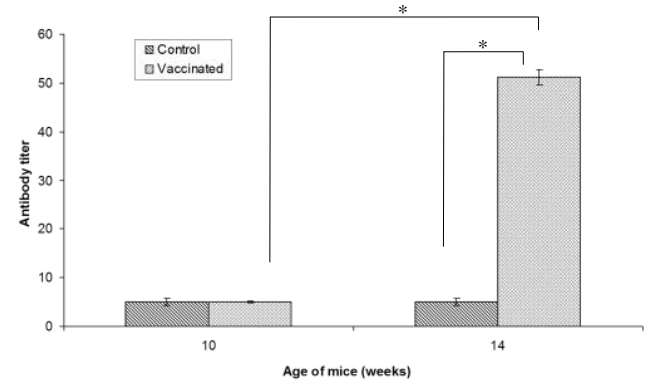

Fig. 3: Serum antibody titers against $S$. pullorum vaccine in mice. Mice were immunized at 10 -week of age and boosted at 12 week of age through $\mathrm{i} / \mathrm{m}$ route at the dose rate of $100 \mu \mathrm{l} / \mathrm{mice}\left(1.25 \times 10^{10} / \mathrm{m}\right.$ CFU). Blood was drawn at 10- and 14-week of age. Serum antibody titer against SP antigen were determined by PHA test. $\mathrm{n}=5$ mice/group. ${ }^{*} P<0.05$ by student's t-test.

\section{Differential Leukocyte Count (DLC) in mice}

To calculate the physiological parameter (DLC), 10-weekold mice were selected. Mice were divided into two groups (A and B). Mice in group A were vaccinated $\mathrm{i} / \mathrm{m}$ with a $50 \mu 1\left(1.25 \times 10^{10} \mathrm{CFU}\right)$ dose of SP vaccine and boostered at 12-week of age using same dose and route. Group B was non-vaccinated control. For blood profiling, a drop of blood was taken from tip of the tail of mice of both groups at 10-, 12-, and 14-week of age. DLC was performed after staining with Wright's stain.

\section{Protection test in mice}

Two weeks after final immunization, mice were challenged intramuscularly with 1.5 mice $\mathrm{LD}_{50}$ of $S$. pullorum and the mortality of challenged mice were monitored for the subsequent 10 days.

\section{Protection test in chickens}

A $10 \mathrm{LD}_{50}$ dose of mice $\left(0.25 \mathrm{ml}\right.$ S. pullorum: $2.22 \times 10^{13}$ $\mathrm{CFU} / 0.25 \mathrm{ml}$ ) was used as a challenge dose for chicken which corresponds $90-100 \%$ mortality at 10-week-old naïve chicken. Two weeks after final immunization both vaccinated and control groups of chicken were challenged and the mortality was monitored for subsequent 10 days.

\section{Passive protection test in chickens}

A $250 \mu \mathrm{l}$ pooled serum from vaccinated or control chicken was mixed with mice $10 \mathrm{LD}_{50}$ dose of $S$. pullorum and incubated at $37^{\circ} \mathrm{C}$ for 30 minutes. The suspension was then administered intramuscularly (total $250 \mu \mathrm{l} /$ chicken) to a group of 10 chicken as per the method described by Saha et al. (2006).

\section{Statistical analysis}

Statistical analysis of antibody titer was performed using paired-t-test. Differences in leukocyte count were analyzed by Mann-Whitney test. Significance in survival rates of chicken and mice were analyzed by Mantle-Cox Log rank test. A $P$-value of $<0.05$ was considered statistically significant.

\section{Results}

Purity and safety test of $S$. pullorum (SP) vaccine

After inoculation of about $0.1 \mathrm{ml}$ of SP vaccine onto BA medium, it was incubated for $24-48$ hours at $37^{\circ} \mathrm{C}$ and the growth of organisms were checked. No growth was detected indicating that the vaccine was biologically pure. After inoculation of $0.5 \mathrm{ml}$ of SP vaccine into the mice $(\mathrm{n}=10)$ subcutaneously, the mice were kept under observation for 10 days. There was no clinical sign or mortality within the observation period. Therefore, the vaccine was safe.

\section{PHA test in chickens}

The pre-vaccination antibody titer was $\leq 4 \pm 00$ in chickens of all groups. After 2- and 4-week of primary vaccination the antibody titers of group A was $89.6 \pm 15.676$ and $57.6 \pm$ 6.4 , respectively. Antibody titer of non-vaccinated control group B was $\leq 4.00 \pm 00$. At both 14- and 16-week after the booster vaccination, the antibody titers of group A were $140.8 \pm 31.35$ and $102 \pm 15.676$, respectively. PHA titer of non-vaccinated control group was $\leq 4 \pm 00$ at both 14 - and 16-week of age (Fig. 1 and Supplementary table 1).

\section{Protection test in chicken}

After the challenge with virulent $S$. pullorum, the birds in both groups were observed for 10 days. All birds of the group A were resistant to virulent challenge exposure whereas all birds in group B showed signs and symptoms 
of infection within two days of post challenge and all control birds died within 7 days of post challenge (Fig. 2).

\section{PHA test in mice}

The pre-vaccination antibody titer was $5 \pm 1.09$. After 2week of booster vaccination the antibody titer was $51.2 \pm$ 7.83 (Fig. 3 and Supplementary table 2).

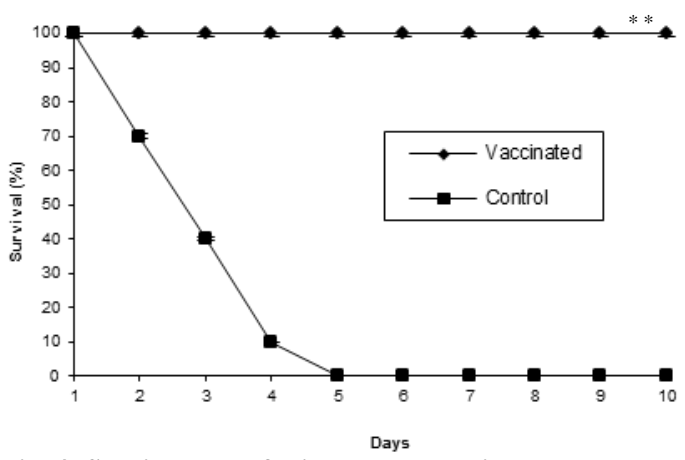

Fig. 4: Survival rate of mice, challenged intramuscularly with virulent isolate of SP antigen. Mice were immunized with SP antigen at 10-week age and boosted at 12-week of age through i/m route at the dose rate of $0.5 \mathrm{ml} / \mathrm{mice}\left(1.25 \times 10^{10} / \mathrm{ml} \mathrm{CFU}\right)$. Survival rate of mice was monitored following $\mathrm{i} / \mathrm{m}$ challenge with $1.5 \mathrm{LD}_{50}$ dose of SP. The survival rate was monitored for subsequent 10 days. $\mathrm{n}=10$ mice per group. ${ }^{* *} P<0.01$ by Mantel Cox Log rank test.

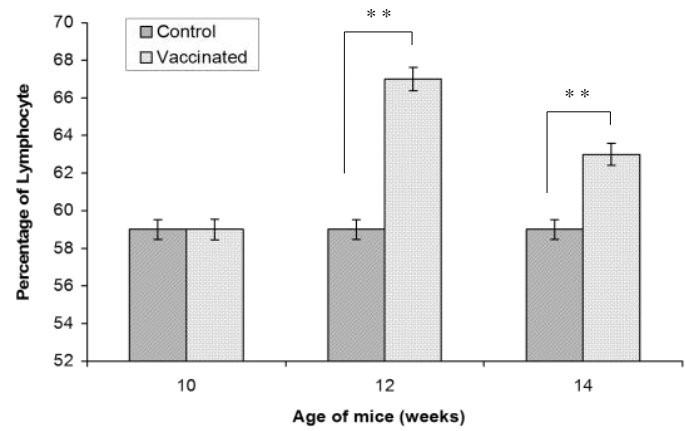

Fig. 5: Percentage of lymphocyte in mice after vaccination with $S$. pullorum. Mice were immunized at 10 -week and boosted at 12 -week of age through $\mathrm{i} / \mathrm{m}$ route at the dose rate of $100 \mu \mathrm{l} / \mathrm{mice}\left(1.25 \times 10^{10} / \mathrm{m}\right.$ $\mathrm{CFU}$ ). The mice were bled at 10-, 12- and 14-week of age. Percentage of lymphocyte in mice after vaccination was performed by Wright's stain. The graph shows the mean $\pm \mathrm{SE}$ ( $\mathrm{n}=5$ mice/group). ${ }^{* *} P<0.01$ by Mann-Whitney test.

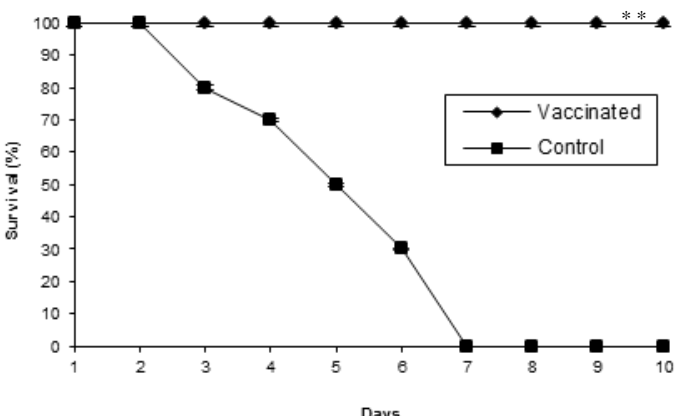

Fig. 6: Survival rate of chicken after passive protection

test. An amount of $250 \mu \mathrm{l}$ of pooled serum from vaccinated chicken was mixed with mice $10 \mathrm{LD}_{50}$ dose of SP antigen and incubated at $37{ }^{\circ} \mathrm{C}$ for 45 minutes. These suspensions were then administered intramuscularly (@500 $\mu \mathrm{l} / \mathrm{chicken)}$ to a group of 10 chickens and mortality was monitored for subsequent 10 days. ${ }^{* *} P<0.01$ by Mantel Cox Log rank test.

\section{Protection test in mice}

After giving the challenge, the mortality of challenged mice was monitored for the subsequent 10 days. All vaccinated mice were protected from the challenge infection. On the other hand, all the control mice died within 5 days of post challenge (Fig. 4).

DLC

DLC was determined in both vaccinated and non vaccinated mice at 10-, 12- and 14-week of age. The lymphocyte count was $59 \pm 0.70,67 \pm 0.94$, and $63 \pm 1.18$, respectively (Fig. 5 and Supplementary table 3).

\section{Passive Protection test in chicken}

After giving the passive protection infection, the mortality of the chickens was monitored for subsequent 10 days. The chickens that received pooled sera from vaccinated animals were protected $(100 \%)$ from lethal challenge infection (Fig. 6).

\section{Discussion}

The SP vaccine is used for prevention of Salmonellosis in layer birds. As an essential part of efficacy test, the $\mathrm{LD}_{50}$ of virulent $S$. pullorum was determined in this study. The efficacy of the experimentally prepared SP vaccine was determined by a combination of PHA titer, protection test, passive protection test and counting of leukocytes. The results of the study showed that vaccine was biologically pure. PHA test of sera from vaccinated and control bird was conducted for the determination of antibody titer following the method described by Tripathy et al. (1970). The pre-vaccinated PHA titers of sera of all vaccinated chickens were recorded as $\leq 4 \pm 0.00$, which was similar to the findings of Ferdous (2008), Yeasmin (2010) and Jannatun (2010)

The antibody titers in this study ranged from 64 to 256 after 2-week of booster vaccination i.e., the lowest antibody titer was 64 , and the highest titer was 256 . This finding is similar to that of Bhattacharyya et al. (2004) who observed that the antibody titer induced by primary vaccination first reached to a peak and declined gradually thereafter. Rahman et al. (2005) used rapid serum plate agglutination test and tube agglutination test to determine the antibody titer. The authors mentioned that antibody titers of the vaccinated birds increased quickly and reached the peak at 2 -week after booster vaccination.

The mean value and SE of antibody titer measuring by PHA test at 2- and 4-week of primary and booster vaccination of group A were $89.6 \pm 15.67,57.6 \pm 6.4,140.8 \pm$ 31.35 , and $102.4 \pm 15.67$, respectively. The highest mean \pm $\mathrm{SE}$ titer was $140.8 \pm 31.35$ at 2 -week after booster vaccination. That result was in agreement with the statement of Rahman et al. (2005), who found that the antibody titer reached peak at 2-week after booster vaccination in chicken. In the present study, it was observed that the PHA titer of group A reached to peak at 15 days after primary vaccination and gradually declined as was observed in 28 days $(P<0.05)$. The same observation was evident after the booster vaccination $(P<0.05)$.

Vaccinated chickens were challenged with virulent $S$. pullorum with a dose of $250 \mu$ l containing $8.9 \times 10^{13} \mathrm{CFU}$ i.e., $10 \mathrm{LD}_{50}$ of mice. The mortality of the inoculated chicken were monitored for the subsequent 10 days and found 
that all chicken survived for more than 10 days. On the other hand, $100 \%$ control chicken were died within 7 days of post infection $(P<0.01)$. These results indicated that SP vaccine prepared by LPVRPC conferred $100 \%$ protection in vaccinated chicken after challenge with virulent $S$. pullorum.

In differential leukocyte count in mice, lymphocyte counts were $59 \pm 0.70,67 \pm 0.94$, and $63 \pm 1.18$ at 10 (pre-vaccination)-, 12-, and 14-week of age, respectively. Vaccination induced an $8 \%$ increase of lymphocyte count in vaccinated mice compared to control group after primary vaccination $(P<0.01)$ but differences were not observed after booster vaccination (Neutrophil and monocyte remained in normal range). The results of passive protection test indicate that humoral immune response might be the principal factor in the protective immune response against $S$. pullorum.

\section{Conclusion}

This study revealed that administration of SP vaccine prepared by LPVRPC conferred $100 \%$ protection in vaccinated chicken after challenging with virulent Salmonella. Antibody titer was peaked on 15-day after both primary and booster vaccination $(P<0.05)$. The results also indicate that humoral immune response might be the principal factor in the protective immune response against $S$. pullorum. The results of this research showed that SP vaccine induced an antibody response both in mice and chicken as determined by PHA test $(P<0.05)$. Vaccinated animals were protected from lethal challenge. Passive transfer of serum conferred protection, suggesting that humoral immune response is crucial for protection.

\section{References}

Barman TK, VD Sharma and S Kumar, 2005. Protective efficacy of maternal antibodies induced by Salmonella toxoid (vaccine). Ind J Exp Biol, 43:163-166.

Bashak LR, 2011. Investigation on the efficacy of Salmonella bivalent vaccine. MS thesis, submitted to the Department of Microbiology and Hygiene, BAU, Mymensingh-2202.

Bhattacharyya DK, H Rahman and HV Murugkar, 2004. Development and evaluation of Salmonella toxoid vaccine for poultry. Ind J Anim Sci, 74: 581-585.

Buxton A and G Fraser, 1977. Animal Microbiology. Vol.1. Blackwell Scientific Publications, Oxford, London, Edinburgh, Melbourne, pp: 85-86.

Das SR, 2011. Efficacy of Salmonella pullorum killed vaccine. MS thesis, submitted to the Department of Microbiology and Hygiene, BAU, Mymensingh-2202.

Dorsey TA, 1963. Studies on Fowl Cholera II. The correlation between biochemic classification and the serologic and immunologic nature of avian Pasteurella multocida. Avian Dis, 7: 393.

Ferdous J, 2008. Immunogenicity study of DLS prepared Salmonella gallinarum vaccine in comparison to commercially available one in layer chicken. MS Thesis, submitted to the Department of Microbiology and Hygiene, BAU, Mymensingh-2202.

Freeman BA, 1985. Burrows text book of microbiology. $22^{\text {nd }}$ Ed. WB Saunders company, Philadelphia, London, Torento, Mexici city, Rio de Janeiro, Sydney, Tokyo, pp: 464-472.
Gifford DH, SM Shane, JM Hugh and BJ Weigler, 1987. Evaluation of biosecurity in broiler breeder. Avian Dis, 31: 339-344.

Haider MG, EH Chowdhury, MAHNA Khan, MT Hossain, MS Rahman, HJ Song and MM Hossain, 2008. Experimental pathogenesis of Pullorum Disease with the Local Isolate of Salmonella entirica serovar. enterica subspecies Pullorum in Pullets in Bangladesh. Korean J Poult Sci, 35: 341-350.

Heddleston KL and RC Reisinger, 1960. Studies on Salmonellosis. IV. Killed fowl typhoid vaccine absorbed on aluminium hydroxide. Avian Dis, 4: 429-435.

Hossain MS, EH Chowdhury, MM Islam, MG Haider and MM Hossain, 2006. Avian Salmonella Infection: Isolation and Identification of Organisms and Histopathological Study. Bangl J Vet Med, 4: 7-12.

Islam MM, MG Haider, EH Chowdhury, M Kamruzzaman and MM Hossain, 2006. Seroprevalence and pathological study of Salmonella infections in layer chickens and isolation and identification of causal agents. Bangl J Vet Med, 4: 79-85.

Islam MM, MM Hossain, MG Haider, EH Chowdhury and M Kamruzzaman, 2007. Seroprevalence and pathological study of Salmonella infections in layer chickens and isolation of causal agents. In Proceedings of the $5^{\text {th }}$ International Poultry show and seminar, 01-03 March, China Friendship Conference Center (CFCC), Sher-e-Bangla Nagar, Dhaka, Bangladesh, pp: 9-15.

Jannatun N, 2010. Preparation of Fowl Typhoid vaccine from field isolates and determination of efficacy. MS thesis, submitted to the Department of Microbiology and Hygiene, BAU, Mymensingh-2202.

Matsumoto M and DH Helfer, 1977. A bacterin against fowl cholera in turkeys: Protective quality of various preparations originated from broth culture. Avian Dis, 21: 382-393.

Office International des Epizooties (OIE), 2008. Fowl Typhoid and Pullorum diseases. Chapter: 2.3.11.

Rahman MM, ZUM Khan and SMH Rashid, 2005. Evaluation of the efficacy of a bacterin against Salmonella gallinarum infection. J Anim Vet Adv, 4: 332-334.

Saha S, F Takeshita, S Sasaki, T Matsuda, T Tanaka, T Tozuka, K Takase, T Matsumoto, K Okuda, N Ishii, K Yamaguchi, DM Klinmnn, KQ Xin and K Okuda, 2006. Multivalent DNA vaccine protects mice against pulmonary infection caused by Pseudomonas aeruginosa. Vaccine, 24: 6240-6249.

Saleque MA, MH Rahman and MI Hossain, 2003. A retrospective analysis of chicken diseases diagnosed at the BRAC poultry diagnostic center of Gazipur. Bangl J Vet Med, 1: 29-31.

Shivaprasad HL, 1997. Pullorum Disease and Fowl Typhoid in Disease of poultry by BW Calnek, H John Barnes, Charles W Beard, Larry R McDougald, YM Saif, $10^{\text {th }}$ Ed, Iowa State University Press, Iowa, USA. pp: 82-93.

Tripathy DN, LE Hanson and WL Mysers, 1970. Passive haemagglutination test with fowl pox virus. Avian Dis, 14: 29-38.

Yeasmin, 2010. On farm investigation on the efficacy of Salmonella vaccine prepared at BAU. MS thesis, submitted to the Department of Microbiology and Hygiene, BAU, Mymensingh-2202. 